\title{
RElato de uma intervenção Na ÁREA da Matemática NO CURSO DE ADMINISTRAÇÃo
}

\author{
EXPERIENCE REPORT ABOUT A MATHEMATICS INTERVENTION IN THE \\ ADMINISTRATION COURSE
}

DOI: http://dx.doi.org/10.23926/RPD.2526-2149.2019.v4.n2.p355-374.id421

\section{Márcia Jussara Hepp Rehfeldt}

Doutora em Informática na

Educação

Universidade Vale do

Taquari (UNIVATES)

mrehfeld@univates.br

\section{Marli Teresinha Quartieri}

Doutora em Educação

Universidade Vale do

Taquari (UNIVATES)

mtquartieri@univates.br

\section{Camila Baseggio Gräff}

Graduação em andamento

em Pedagogia

Universidade Vale do

Taquari (UNIVATES)

milagraff@gmail.com
Resumo: Este relato tem por objetivo compartilhar e discutir os resultados decorrentes de intervenções realizadas com dois distintos grupos de alunos do curso de Administração na Universidade do Vale do Taquari, RS. As atividades, trabalhadas ao longo de um semestre, em 2018, foram acompanhadas por duas professoras que, de forma conjunta, planejaram e desenvolveram as tarefas matemáticas. No decorrer do semestre, os alunos, em grupos, planejaram um empreendimento, por escrito, realizando um plano de ações, de tal forma que todos os conteúdos estudados na disciplina estivessem contemplados no projeto. Os trabalhos foram escritos e entregues aos professores e socializados com os colegas em aula. Os resultados dos dois questionários de avaliação apontam que entre os diversos temas abordados, cerca de $70 \%$ dos assuntos envolveram o ramo alimentício; os discentes usaram corretamente o aprendizado em aula, aplicando as regras básicas do uso de escala e de gráficos. Em geral, por meio da atividade, conseguiu-se atingir os objetivos, pois os alunos compreenderam e aplicaram os conteúdos desenvolvidos e listados como relevantes para futuros administradores.

Palavras-chave: Matemática Aplicada a Negócios. Administração. Empreendimento.

\begin{abstract}
This report aims to share and discuss the results of interventions performed with two distinct groups of graduation students of Administration at the University of Vale do Taquari, RS. Under supervision of two professors who planned and developed mathematical tasks, the students created a fictional action plan of an enterprise based on all the contents studied during the course. The action plans were written and delievered to the professors. Yet, the ideas were shared and discussed with classmates. The results of the two evaluation questionnaires point out that among other topics, about $70 \%$ of the fictional enterprises were related to food production and commercialization; the students used correctly the skills learned class and were able to explore the basic rules of using scales and graphics. In general, the objectives of the proposed through the activity were achieved, since the students understood the purpose of the activity and were able to properly apply and use concepts and techniques frequently required in their professional activities as administrators.
\end{abstract}

Keywords: Mathematics applied to business; Administration; Enterprise 


\section{INTRODUÇ̃̃o}

Uma das profissões mais antigas e ainda muito requisitada e indispensável está relacionada à administração. Souza (2015) afirma que, já antes de Cristo, os antigos povos procuravam maneiras de administrar seus problemas. De tais práticas, surgiu a profissão de administrador, que auxilia hoje no gerenciamento das empresas. Uma das principais diferenças do administrador atual dos mais primitivos está no modelo utilizado. Em tempos remotos, não se tinha ideia do que as escolhas poderiam ocasionar para uma empresa, pois não havia tecnologias e estratégias inovadoras como no século atual (SILVA, 2015). Hoje os administradores buscam inovar e planejar, com o objetivo de prever os resultados para a tomada de decisão. Por isso, necessita-se de profissionais capacitados com alguns requisitos para liderar uma empresa. Com base em vasta pesquisa virtual, percebe-se que as vagas de emprego e guias profissionais relacionam o administrador a uma pessoa com habilidade com números, comunicativa e ética, que busca aperfeiçoamento profissional, sabe argumentar, é empreendedora, auxilia nos recursos financeiros e administrativos: pagamento e gestão de contas (EDUCACIONAL, 2016; INDEED, 2019). Assim, infere-se que os administradores são importantes para as corporações e, consequentemente, para a sociedade.

Nesse sentido, busca-se auxiliar na formação dos alunos do curso de administração, proporcionando ações que contornem problemas de gestão empresarial. Assim, duas docentes da disciplina Matemática Aplicada a Negócios planejaram aulas de forma conjunta, a partir da ementa disponibilizada no Projeto Pedagógico do Curso de Administração. Os conteúdos foram explorados em forma de exercícios, desafios, estudos de casos, fazendo os alunos refletirem acerca da aplicabilidade da Matemática no curso. Para verificar se as habilidades da disciplina foram desenvolvidas, solicitou-se aos discentes que, em pequenos grupos, elaborassem a proposta de um empreendimento, contemplando um plano de ações, de qualquer ramo, segundo os interesses do grupo. Assim, ao longo do semestre, à medida que os conteúdos eram explorados, foram incorporados aos projetos, que deveriam abordar os conteúdos ensinados nas aulas. Com base em tais informações, o presente artigo objetiva descrever, discutir e compartilhar os resultados decorrentes dessa intervenção realizada com dois distintos grupos de alunos do curso de Administração na Universidade do Vale do Taquari. Tal intervenção abordou uma metodologia diferenciada no sentido de buscar desenvolver os conteúdos Matemáticos, com enfoque num plano empresarial construído pelos próprios discentes, aplicando o que aprenderam ao longo do semestre. 


\section{REFERENCIAL TEÓRICO}

A gestão das empresas vem se modificando com o passar dos anos, o que altera as exigências de formação do profissional. Os empresários buscam trabalhadores diferenciados, com diversas competências, para tornar a empresa mais competitiva frente aos concorrentes. Então, qual seria o real papel do administrador de empresa, na visão de distintos autores?

Para Santos, Capelari e Sperandio (s/d, p. 5), "o papel do administrador pode ser resumido como sendo aquele responsável pela ajuda a todos os membros e unidades da organização". Assim, para esses autores, sem um gestor ou um indivíduo que ajude os demais, não haverá uma boa administração empresarial, o que, a longo prazo, pode desencadear a falência da companhia.

De acordo com Machado (1998), a Administração [em si] é um estudo no qual se desenvolvem processos de planejamento, organização e controle. Assim, a habilidade para lidar com números, espírito de liderança e desenvoltura para argumentar são predicados imprescindíveis ao administrador. O autor ainda afirma que, diante das reivindicações, da globalização da economia e dos avanços tecnológicos, a função do administrador vem se tornando mandatória (MACHADO, 1998).

Fonseca e Silva (2012, p. 5, grifos dos autores) mencionam que,

na prática, ele [o administrador] tem a missão de organizar e aplicar políticas econômicas, administrativas, desenvolver programas de ação, idealizar planos de ação, fazer orçamentos para laudos e projetos, esquematizar e controlar pesquisas, desde a edição até o tratamento estatístico. Pode, também, avaliar a estrutura de uma empresa, coordenar as funções das equipes de trabalho e averiguar sua adaptação à estrutura a ao porte do empreendimento.

Percebe-se que o administrador é de fundamental importância na gestão de um empreendimento. Para isso, quem assume este cargo deve ser um líder, necessita organizar e planejar os recursos administrativos e econômicos com ampla visão, para desenvolver novos programas e recursos e assim estruturar a empresa, o que exige conhecimentos matemáticos.

Em relação aos conhecimentos matemáticos requisitados, destaca-se que alguns refletem a necessidade de raciocínio lógico-matemático. Pesquisas com o intuito de verificar a real aplicabilidade matemática apontam que, pelo menos, três habilidades [de um administrador] numa relação de dez dependem de aplicações matemáticas (FERREIRA e SILVA, 2012). Com enfoque mais específico na matemática, conforme esses autores,

na administração, a matemática é útil em diversas situações: na elaboração de um planejamento, no controle do fluxo de mercadoria, proporciona também soluções de problemas empresariais, seja na área de recursos humanos, produção, 
comercialização, de finanças ou na própria administração geral (FERREIRA e SILVA, 2012, p. 3).

Nesse sentido, um administrador deve desempenhar muitas funções, sendo uma delas operar com números. Neste contexto, os cursos de administração abordam conteúdos matemáticos necessários para tal cargo. Fuentes, Lima e Guerra (2009) alegam que padrões matemáticos vêm propiciando soluções a diferentes problemas e/ou circunstâncias organizacionais nas disciplinas de Recursos Humanos, Produção, Marketing e, sobretudo, no campo de Finanças. Concordando, Santos, Capelari, Sperandio (s/d, p. 9) afirmam que,

a matemática é uma disciplina importante no curso [de administração], porque faz parte de todo o patrimônio cognitivo da Humanidade. O ensino matemático pode contribuir até com uma formação humanística; enriquecedor do conhecimento intelectual; utiliza-se do pensamento lógico, demonstrativo, intuitivo, criativo, de imaginação e de raciocínio, características essenciais de um administrador.

A partir da referida citação, infere-se que a Matemática nos cursos de Administração é relevante, já que contribui na análise e na identificação de problemas que podem surgir durante a trajetória do gestor. Esquivel et al. (2008, p. 2) reforçam essa ideia afirmando que "a Matemática é tão relevante no meio acadêmico quanto em diferentes momentos do dia a dia, sendo intrínseca ao raciocínio, à crítica e ao domínio de circunstâncias”.

Tal relevância também é compreendida na Universidade do Vale do Taquari, pois, no currículo do curso de Administração, há a disciplina de "Matemática Aplicada a Negócios", cujos objetivos perpassam a identificação de problemas, formulação e implantação de soluções para as questões, cujas competências, supracitadas, são familiares e necessárias ao administrador. Retomam-se as principais que englobam o planejamento; o controle de mercadoria (quando houver); solução de problemas (comércio, finanças, administração); organização administrativa da empresa; orçamentos e tratamentos estatísticos. Julgando necessárias essas habilidades, organizaram-se as atividades com o intuito de desenvolvê-las. Além disso, a disciplina procura desenvolver o raciocínio lógico, crítico e analítico. Entre as habilidades de um administrador, segundo Esquivel et al. (2008, grifos dos autores), está a capacidade de usar "o raciocínio lógico, crítico e analítico, operando com valores e formulações matemáticas e estabelecendo afinidades formais e causais entre fatos”.

Conclui-se assim que a Matemática no contexto administrativo é importante para a formação do profissional, pois auxilia na utilização do pensamento matemático e desencadeia a compreensão das atividades reais, lidando com conceitos e técnicas facilitadoras dos cálculos necessários. Destaca-se, ainda, que a disciplina objetiva explorar conceitos de proporcionalidade, matrizes, áreas, cubagem e programação linear e funções do $1^{\mathrm{o}}$ grau; 
interpretar, descrever e analisar dados vinculados a situações de negócios; desenvolver a autonomia por meio da proposição de soluções para problemas vinculados a negócios.

\title{
3 Metodologia
}

A metodologia aplicada na pesquisa é de cunho qualitativo. Segundo Freitas e Jabbour (2011, p. 10), "a principal vantagem da abordagem qualitativa, em relação à quantitativa, referese à profundidade e à abrangência, ou seja, o 'valor' das evidências que podem ser obtidas e trianguladas por meio de múltiplas fontes". Ou seja, utiliza-se a pesquisa qualitativa para entender o porquê, os motivos, as opiniões de sujeitos envolvidos. Esse tipo de pesquisa fornece informações sobre algum problema, bem como, é utilizada para descobrir tendências dos participantes em relação ao tema investigado.

Um dos meios utilizados para realizá-la é o estudo de caso. De acordo com Godoy (1995, p. 25), “o estudo de caso se caracteriza como um tipo de pesquisa cujo objeto é uma unidade que se analisa profundamente [...], que visa ao exame detalhado de um ambiente, de um simples sujeito ou de uma situação em particular". De tal forma que,

\begin{abstract}
no estudo de caso, o pesquisador geralmente utiliza uma variedade de dados coletados em diferentes momentos, por meio de variadas fontes de informação. Tem como técnicas fundamentais de pesquisa a observação e a entrevista. Produz relatórios que apresentam um estilo mais informal, narrativo, ilustrado com citações, exemplos e descrições fornecidos pelos sujeitos, podendo ainda utilizar fotos, desenhos, colagens ou qualquer outro tipo de material que o auxilie na transmissão do caso (GODOY, 1995, p. 26).
\end{abstract}

Ainda, Moreira (2011, p. 86, grifos do autor) afirma que o estudo de caso é utilizado "há muito tempo, em campos como o direito, a medicina, a psicologia e a administração". Reforça-se tal citação com a fala de Serrano (1998, p. 91), para quem

as propriedades essenciais de um estudo de caso qualitativo são a particularização (se centram em uma situação, evento, programa ou fenômeno particular), a descrição (o produto final é uma descrição rica e densa do objeto de estudo), e a indução (baseiamse no raciocínio indutivo; as teorias, os conceitos ou hipóteses surgem de um exame dos dados fundados no contexto mesmo).

Percebe-se, dessa maneira, que os métodos adotados estão em consonância com esta pesquisa, visto que tem por objetivo analisar as falas dos alunos, seus relatos e suas estratégias, utilizando a coleta de dados de distintas maneiras para expor os resultados.

Esse estudo foi realizado ao longo do semestre, com duas turmas distintas e diferentes professoras, que planejaram em conjunto as aulas e as ações. Em cada aula, as docentes orientavam os alunos nos conteúdos estudados, na sua aplicabilidade e como poderiam ser contemplados no trabalho final. Inicialmente, foram explorados assuntos relacionados à regra 
de três, porcentagem, escalas, funções de $1^{\circ}$ grau aplicadas às situações-problema. Em seguida, o estudo de sistemas lineares, matrizes, noções de cubagem e área. O trabalho final da disciplina era propor um empreendimento com os conteúdos explorados em aula durante o semestre. Nas aulas, foi exemplificada a aplicabilidade dos conteúdos para que os discentes estabelecessem relações entre os temas e o planejamento de suas futuras empresas.

Todavia, conforme aponta Lisboa e Lucino (2015, p. 31), para que se obtenha uma significativa aprendizagem, "o professor deve ser também um pesquisador, e despertar nos seus alunos o mesmo hábito de buscar o conhecimento além do que é trazido e apresentado em sala de aula". Ademais, "a metodologia de ensino do professor deve ter relação entre teoria e prática para uma melhor compreensão por parte dos alunos, de modo que eles entendam o porquê de estudar aquele conteúdo, que faça sentido e tornando-o significativo, o que desencadeia no ensino-aprendizagem" (LISBOA e LUCINO, 2015, p. 30). Assim, no trabalho, os alunos puderam inserir o horário de atendimento, o capital social, o CNPJ, a inscrição estadual e municipal, o alvará de licença, o pró-labore e os descritivos da empresa em si. A partir dessas informações, poderiam mencionar algo sobre os clientes/fornecedores, analisar a possível concorrência e, então, partir para o planejamento do empreendimento.

A seguir, os alunos calcularam a superfície do espaço físico do local onde seria a sede da empresa, enfocando escala, área, perímetro e cálculos de porcentagem. Houve menções a cubagem e volume, regra de três, matrizes, programação linear, a um plano de negócio, à análise financeira do estabelecimento, incluindo os custos fixos e variáveis, além de mensuraram o ponto de equilíbrio, destacando como e quando poderiam obter lucro.

Portanto, a prática abordada nesse estudo buscou relacionar a teoria com a prática, na proposta do empreendimento planejado pelos grupos. No final do semestre, os projetos foram apresentados e entregues. Para fins de avaliação, propôs-se um questionário para verificar a opinião dos alunos acerca dos trabalhos dos colegas, dos seus projetos e da metodologia adotada pelas professoras. Com base em tais documentos, foi realizada a análise de dados, cujos resultados estão descritos a seguir.

Os efeitos do discurso pré-construído é que oferecem a dimensão do hiperconceito da matemática, o que se deve a sua metalinguagem, que é considerada de difícil acesso. Não é o discurso em si que oferece este hiperconceito à matemática, porque ele é relativo à memória, já que está disperso em todas as falas, em todos os lugares de significação e por sua vez esconde-se nas relações entre os sujeitos, aluno e professor. Estes lugares de significação dados à matemática interferem na relação entre o sujeito que ensina e o sujeito que aprende. A ruptura destes significados é impossibilitada, pois os efeitos do discurso pré-construído estão apagados pela pedagogização da matemática, a qual fica mediando o acesso aos saberes que constituem o discurso matemático (SILVEIRA, 2011, p. 6). 
Retoma-se nesta seção a finalidade desse trabalho, qual seja, analisar os resultados decorrentes da prática realizada, abordando uma metodologia diferenciada para desenvolver conteúdos Matemáticos num curso de Administração. Para ilustrar os resultados obtidos, essa seção é dividida em três blocos. No primeiro (1), apresentam-se os negócios propostos pelos alunos. No segundo (2), algumas aplicações encontradas nos trabalhos dos alunos. No último bloco (3), discutem-se os resultados obtidos do questionário aplicado aos alunos no final do semestre.

\subsection{TEMAS/NEGÓCIOS PLANEJADOS:}

No Quadro 1, apresenta-se o resumo das empresas planejadas pelos alunos com o intuito de ilustrar de forma breve os trabalhos propostos.

Quadro 1 - Nomes das empresas e as finalidades

\begin{tabular}{|c|c|}
\hline $\begin{array}{l}\text { Nome da } \\
\text { empresa }\end{array}$ & Finalidade \\
\hline $\begin{array}{l}\text { I Love Pet's } \\
\text { Pet Shop }\end{array}$ & $\begin{array}{l}\text { Microempresa voltada aos cuidados dos animais, em particular cães e gatos. Nesse } \\
\text { negócio, os serviços são a tosa, banho, produtos alimentícios para animais e uma ampla } \\
\text { linha de acessórios. }\end{array}$ \\
\hline Posto Pidalev & $\begin{array}{l}\text { Comércio de combustível com propósito de oferecer produtos de qualidade, aliado a um } \\
\text { bom preço e ótimo atendimento ao cliente. }\end{array}$ \\
\hline $\begin{array}{ll}\text { Loja } & \text { de } \\
\text { calçados } & \\
\text { esportivos } & \text { Ta } \\
\text { no Pé } & \end{array}$ & Comércio voltado ao ramo comercial de calçados. \\
\hline Refúgio Pub & $\begin{array}{l}\text { Espaço amplo para fornecer ao cliente o maior conforto para desfrutar cervejas, drinks e } \\
\text { caipirinhas disponíveis, sem contar os petiscos. }\end{array}$ \\
\hline Weihensbier: & $\begin{array}{l}\text { Com o objetivo de atingir } 10 \% \text { do mercado das cervejas artesanais da região, a } \\
\text { propriedade teve um alto investimento em equipamentos de produção. Criaram-se } \\
\text { mecanismos modernos que deixam o processo seguro e a cerveja maravilhosa. }\end{array}$ \\
\hline Green Future & Empresa voltada aos orgânicos, alimentos hoje indispensáveis numa dieta alimentar. \\
\hline S.O. S Beleza & $\begin{array}{l}\text { Essa empresa foi descrita pelas discentes como uma proposta para as pessoas que buscam } \\
\text { agilidade na agenda de salões de beleza por meio de um aplicativo, onde mesmo que não } \\
\text { queiram sair de suas casas, poderão marcar/desmarcar horários em salões locais. Para isso, } \\
\text { a empresa terá uma sede com área de } 70 \mathrm{~m}^{2} \text { que foram divididos em } 6 \text { cômodos. }\end{array}$ \\
\hline $\begin{array}{l}\text { Dream Night } \\
\text { Pub }\end{array}$ & $\begin{array}{l}\text { Uma microempresa voltada para o público jovem que busca se divertir numa danceteria } \\
\text { com vários estilos musicais, opções múltiplas de bebidas e um sistema diferenciado de } \\
\text { comandas e cardápio. }\end{array}$ \\
\hline $\begin{array}{l}\text { Me Gusta } \\
\text { Doces } \\
\text { Gourmet }\end{array}$ & $\begin{array}{l}\text { De acordo com os administradores: "fabricar doces finos é uma atividade lucrativa" visto } \\
\text { que estão ganhando mais espaço no mercado. Esses novos docinhos buscam a criatividade } \\
\text { e a ousadia de quem os prepara. Mas será que os brigadeiros são rentáveis de fato? }\end{array}$ \\
\hline $\begin{array}{l}\text { La Kombí de } \\
\text { Açaí }\end{array}$ & $\begin{array}{l}\text { Microempresa móvel estilo "food truck" que busca atender as exigências do público que } \\
\text { aprecia açaí de qualidade e com um sabor único. Esse comércio possui dois tipos distintos } \\
\text { de copos: } 250 \mathrm{ml} \mathrm{e} 400 \mathrm{ml} \text {, com preço acessível e ainda com a possibilidade do cartão de } \\
\text { crédito. }\end{array}$ \\
\hline $\begin{array}{l}\text { Cervejaria } \\
\text { Morro Pelado }\end{array}$ & $\begin{array}{l}\text { Estabelecimento fundado em } 2018 \text { busca oferecer ao mercado consumidor um novo } \\
\text { conceito da cerveja artesanal, sendo disponibilizadas duas cervejas: Pilsen e Apa. }\end{array}$ \\
\hline $\begin{array}{l}\text { Mini Pizzas } \\
\text { Santotti }\end{array}$ & $\begin{array}{l}\text { De acordo com uma pesquisa realizada pelos donos do comércio, as pizzas são o } \\
\text { segundo alimento mais consumido pelos brasileiros dentro da categoria das massas. }\end{array}$ \\
\hline
\end{tabular}




\begin{tabular}{|l|l|}
\hline & $\begin{array}{l}\text { Para isso, a empresa produziria minipizzas com opcional de tele-entrega, e ainda um } \\
\text { espaço confortável para os clientes que desejam saborear na pizzaria. }\end{array}$ \\
\hline BestBurger & $\begin{array}{l}\text { Empresa voltada ao ramo alimentício com um espaço aconchegante e agradável" é os } \\
\text { princípios dos criadores de tal hamburgueria. Os mesmos buscam atuar no ramo } \\
\text { alimentício vendendo hambúrgueres tradicional, frangofit, bacon, calabresa e misto. }\end{array}$ \\
\hline Ponto Vip Car & $\begin{array}{l}\text { Espaço de lavagem de carros com um toque feminino que necessita de pouco } \\
\text { investimento inicial é o negócio de duas sócias formadas em Administração. A empresa } \\
\text { dispõe de diversos serviços podendo ser de veículos de pequeno porte aos de grande porte } \\
\text { com lavagem simples ou completa. }\end{array}$ \\
\hline HouseBeer & $\begin{array}{l}\text { Distribuidora de bebidas no Vale do Taquari, com 360m² de espaço que busca } \\
\text { comodidade para os clientes que desejam tomar uma bebida com os amigos e se divertir } \\
\text { em mesas de jogos. }\end{array}$ \\
\hline $\begin{array}{l}\text { Mundo do } \\
\text { Hambúrger }\end{array}$ & $\begin{array}{l}\text { Empreendimento voltado para o meio alimentício com quatro opções de hambúrgueres e } \\
\text { três acompanhamentos opcionais. }\end{array}$ \\
\hline $\begin{array}{l}\text { Cosa Mostra } \\
\text { Caffetteria }\end{array}$ & $\begin{array}{l}\text { Excelência” é o princípio dos donos desta cafeteria que tem por missão a participação no } \\
\text { cotidiano das pessoas através de uma pequena xícara de café. }\end{array}$ \\
\hline
\end{tabular}

Fonte: Das autoras, 2018.

Foram apresentados 17 trabalhos distintos nos ramos alimentício e bebidas (tanto na produção, quanto na comercialização) e de prestação de serviços (na área animal, estética, lazer). O ramo que se destacou foi o alimentício, com 12 trabalhos, ou seja, mais de $70 \%$ interessou-se por este ramo. De acordo com a ERJ (SEBRAE, 2012, p. 4),

cerca de $81 \%$ das empresas do setor de alimentos estão concentradas em três atividades: restaurantes e outros serviços de alimentação e bebidas, com $41 \%$; comércio varejista de produtos alimentícios, bebidas e fumo, com $26 \%$; e pecuária, com $14 \%$ do total de estabelecimentos.

Os alunos do curso de Administração perceberam que atividades de restaurante, alimentação e bebidas estão em expansão. Santos, França e Santos (2007) também revelam que o tema alimentação é oportuno para despertar o interesse do aluno. Também se percebeu uma atenção a novas tendências, como a produção de orgânicos e a criação de aplicativos. Por meio do aplicativo, é possível agendar horários livres em salões de beleza próximos da residência, o que facilita o deslocamento e o interesse do cliente por determinado serviço. Já os comércios tradicionais foram pouco explorados, o que evidencia que os jovens estão atentos a novas formas negócios e a tecnologia está ganhando cada dia mais espaço. Nesse sentido, Kohn e Moraes (2007, p. 5) afirmam que

a sociedade transita hoje no que se convencionou denominar Era Digital. Os computadores ocupam espaço importante e essencial no atual modelo de sociabilidade que configura todos os setores da sociedade, comércio, política, serviços, entretenimento, informação, relacionamentos.

As tecnologias de informação estão presentes em todos os ramos de atuação de um administrador: comércio, política, serviços e afins. Cabe à empresa, ao administrador averiguar e analisar a melhor forma de disseminar e trabalhar com as tecnologias. 


\subsection{ANÁliSe DE ALGUMAS APLICAÇõeS dOS CONTEÚdOS UTILIZADOS PELOS ALUNOS}

Nesta seção, discutem-se alguns conteúdos utilizados pelos alunos nos negócios, como o uso da porcentagem. Assim, busca-se explicitar quatro estratégias propostas pelos alunos consideradas relevantes. A seguir, alguns procedimentos adotados pelos estudantes.

a) Ponto de Equilíbrio descrito pelo grupo que propôs a empresa Mundo do Hambúrguer:

Em uma empresa, é necessário estabelecer um ponto de equilíbrio. Conforme Crepaldi (1999), uma empresa está num ponto de equilíbrio financeiro, quando não apresenta nem lucro e nem prejuízo. Por isso, é necessário um profissional que acompanhe as vendas da empresa e calcule o ponto de equilíbrio, com o objetivo de fazer com que a empresa não tenha custos desnecessários, tampouco produtos que não sejam lucrativos. Desse modo, o interessante desse comércio é o custo e a quantidade dos hambúrgueres que devem ser vendidos. O valor unitário do sabor bacon é mais significativo comparado ao de carne, e, mesmo assim, ainda é necessário vender a mesma quantia de cada um (229), independente do valor. Sendo assim, o fixo mensal da empresa era de $\mathrm{R} \$ 1.208,00$ ao mês. Logo, o lucro por hambúrguer de carne era de 2,58 e o de bacon é 2,70 (R\$ 0,12 mais caro), mas os administradores de tal loja queriam vender os dois sabores e por isso calcularam o ponto de equilíbrio com os dois.

Os alunos, inicialmente, levantaram os gastos fixos mensais. Após, calcularam a margem de contribuição, utilizando os custos fixos subtraídos dos custos variáveis. Por fim, aplicaram a fórmula:

$$
\text { Ponto de Equilíbrio }=\frac{\text { Gastos Fixos }}{\text { Margem }}
$$

Na Figura 1, observa-se o procedimento do grupo na resolução. O custo fixo mensal deles era de $\mathrm{R} \$ 1.208,00$ (retângulo verde); o lucro por hambúrguer de carne era de 2,58 e o de bacon é 2,70 ( $\mathrm{R} \$ 0,12$ mais caro). Esses valores foram somados (retângulo azul) e, posteriormente, divididos pelo custo fixo. 
Figura 1 - Procedimento adotado pelo grupo

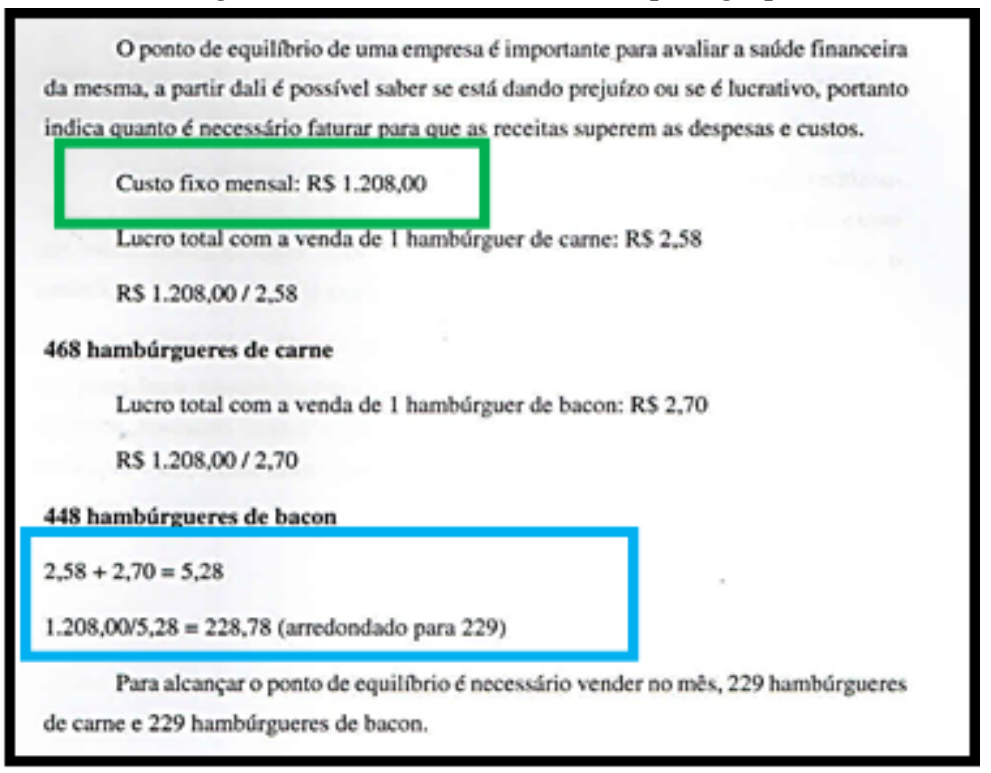

Fonte: Das autoras, 2018.

b) Cubagem e volume, empresa S.O.S Beleza:

Esse trabalho chama atenção em função do raciocínio dos alunos. Em vez de calcularem apenas o volume de algum objeto, pensaram em documentos dispostos em pastas ou outros documentos que ficam agrupados. Na clínica projetada, planejaram uma estante para armazenar os cadernos anuais da empresa. Sendo assim, para desenhar a planta baixa, calcularam o volume do móvel. Além disso, pensaram em dispor em torno de sessenta pastas. Desta forma, calcularam a possibilidade de dispor estas pastas na estante, como segue na Figura 2.

Figura 2 - Utilização da cubagem e volume no escritório do grupo

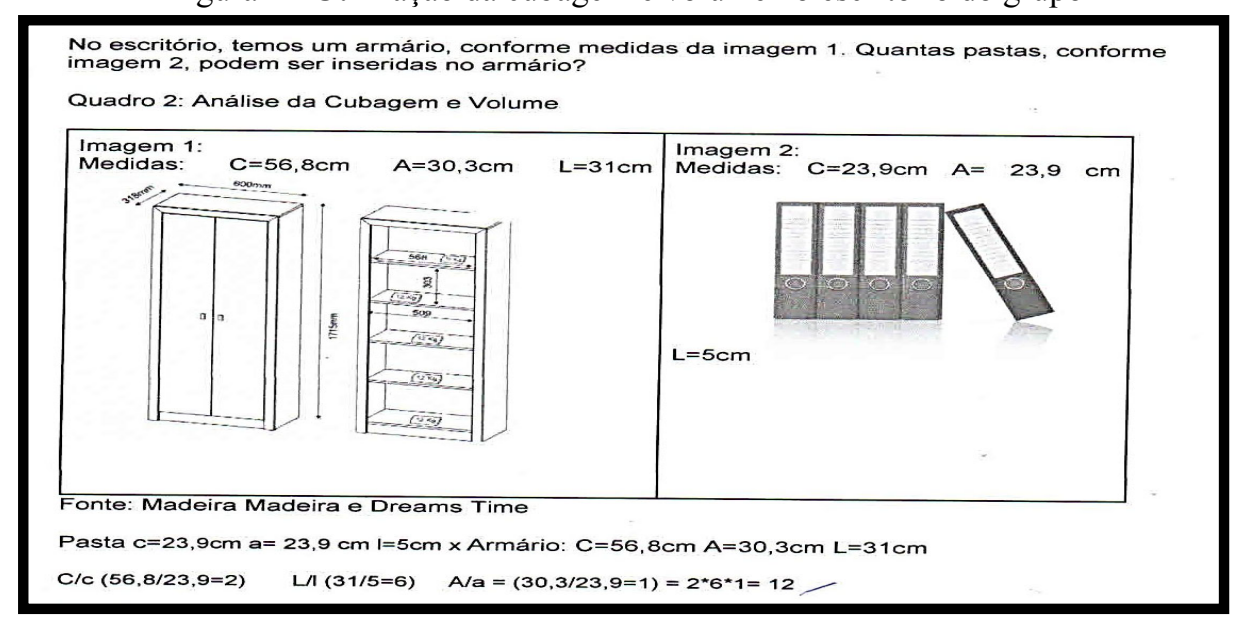

Fonte: Das autoras, 2018.

Observa-se, na Figura 3, que os alunos selecionaram as medidas da estante e dos livros. Após, dividiram o comprimento da estante pelo dos livros; a altura da estante pela dos livros; e a largura do armário pela dos livros. No fim, multiplicaram os resultados totalizando 12 (doze). 
$\mathrm{Na}$ última parte da conta (não expressa na figura), os alunos multiplicaram o doze por cinco (número de prateleiras), chegando ao produto de 60 pastas. Assim, a estante teria dimensões suficientes para encaixar as pastas necessárias.

c) Exemplo de escala e área utilizada pela empresa Ponto Vip Car

Outro assunto usado foi a escala. Assim, o grupo propôs o desenho de uma lavadora de carros, com espaço para a circulação de clientes e proprietários. Desta forma, surgiu a planta baixa representada na Figura 3.

Figura 3 - Planta baixa do espaço Ponto Vip Car

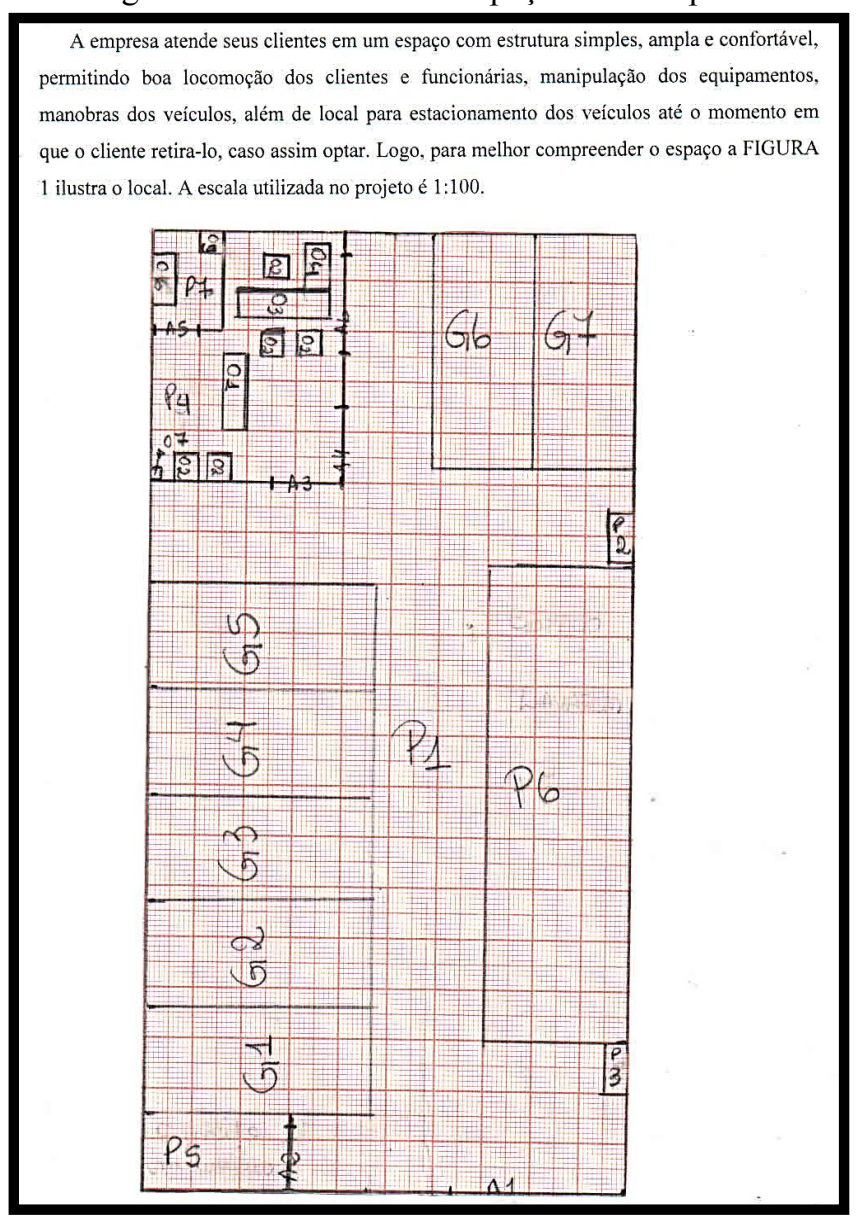

Fonte: Das autoras, 2018

Os espaços denominados por G são os estacionamentos, onde os clientes poderão deixar o carro para posterior lavagem. Os pontos P2 e P3 são registros de água e luz. P1 é a área total de $190 \mathrm{~m}^{2}$. P4 é local de espera, caso os clientes queiram aguardar o atendimento. O depósito de materiais do estabelecimento é o P5 e o espaço de lavagem é o P6, com uma sala pequena onde também há um lavabo. Para encontrar a área de circulação do local, temática também explorada em aula, o grupo ilustrou na Figura 4, o cálculo das áreas. 
Figura 4 - Mensuração das áreas na planta baixa do local

\begin{tabular}{|c|}
\hline 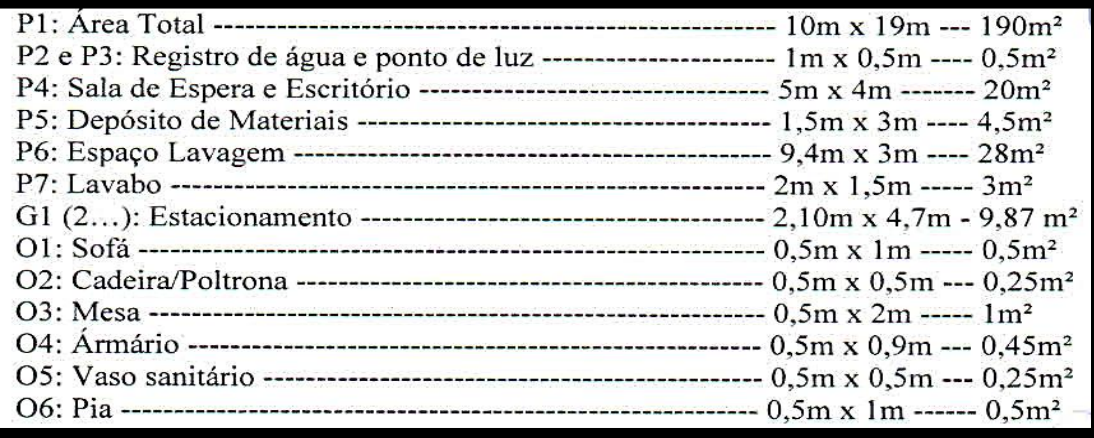 \\
\hline
\end{tabular}

Fonte: Das autoras, 2018.

O grupo somou as áreas dos objetos e dos espaços e as subtraiu da área total (P1), o que resultou num espaço de circulação de $121,18 \mathrm{~m}^{2}$. Ressalta-se que a escala é uma estratégia de aproximação do real; por isso, é importante em cursos de Administração, uma vez que poderão calcular as necessidades que surgirão ao longo da trajetória, na empresa em que trabalham, como, por exemplo, reformas ou adaptações de espaços físicos, quando terão que calcular áreas e poderão usufruir das escalas (CASTRO, 1995).

d) Diferencial do trabalho, Refúgio Pub:

Alguns trabalhos projetados nessa disciplina consultaram páginas da web. Já outros consultaram os colegas da Universidade. Assim, antes de planejar seu negócio, fizeram uma consulta breve, ou seja, uma pesquisa de opinião com os colegas sobre um pub. Para isso, desenharam o gráfico expresso na Figura 5.

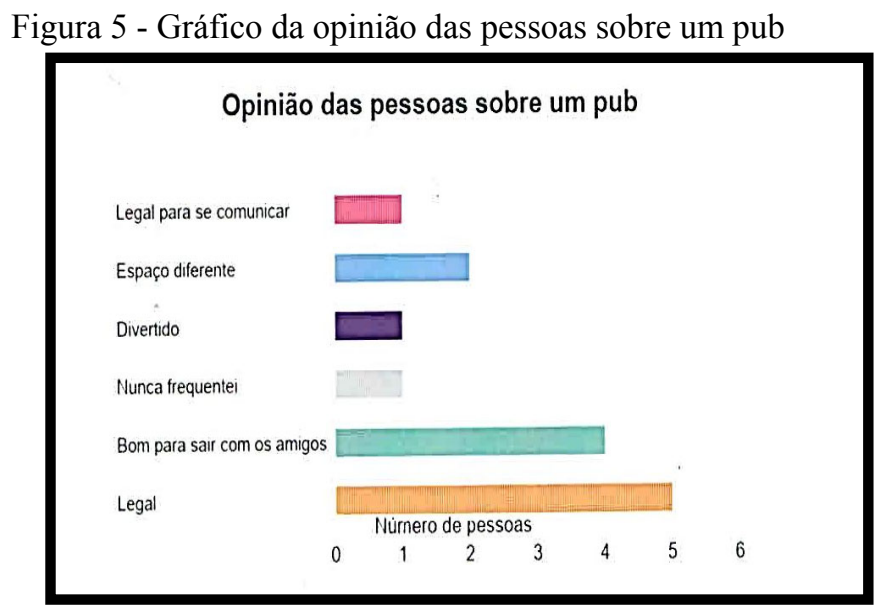

Fonte: Das autoras, 2018

A maioria dos investigados declarou que um pub é "legal"; um bom local para sair com os amigos; por ser um espaço diferente, divertido, é bom para a comunicação. Assim, gráfico é um tema/conteúdo relevante no ensino de Matemática. Para Monteiro (1998, p. 11), 
o fato de gráficos permitirem a representação de dados em diversos conteúdos amplia a importância de tais sistemas de representação, uma vez que não se relacionam apenas com conteúdos da matemática, mas de fato permitem tratamento de informações de diversas outras áreas de conhecimento.

Ademais, é necessário que um administrador tenha conhecimento e capacidade de elaborar gráficos para que possa mostrar de forma visual alguns comportamentos, "permitindo uma atuação de forma preventiva, efetuando ações corretivas no momento em que ocorrerem desvios, mantendo-o dentro de condições pré-estabelecidas” (FUTURO e SILVA, 2007).

e) Aplicação de regra de três e áreas do negócio I Love Pets:

O grupo que propôs o negócio I Love Pets identificou que, inicialmente, precisaria realizar uma reforma no espaço escolhido para o empreendimento. Assim, passou a efetuar cálculos de áreas e porcentagens.

Figura 6 - Dados numéricos do grupo

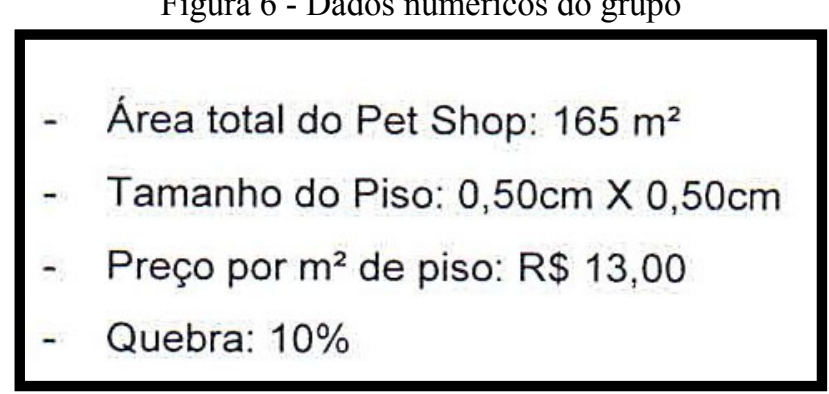

Fonte: Das autoras, 2018.

A partir desses dados, fizeram os cálculos que seguem na Figura 8:

Figura 7 - Cálculos realizados pelo grupo para obter quantidade de pisos e valores

Área do piso:
$0,50 \mathrm{~cm} \times 0,50 \mathrm{~cm}=0,2500 \mathrm{~m}^{2}$
Total de pisos a serem utilizados:
$165 / 0,2500=660$
$660+10 \%=726$ pisos devem ser utilizados no total
Preço total:
$165+10 \%=182$
$182 \times \mathrm{R} \$ 13,00=\mathrm{R} \$ 2.366,00$

Fonte: Das autoras, 2018.

O grupo concluiu que seriam necessários 726 pisos, num valor de $\mathrm{R} \$ 2.366,00$. Observase que uma única atividade envolve diversas habilidades na formação de um administrador competente. A atividade do grupo "I Love pets" abordou principalmente os conteúdos de 
porcentagem, além de alguns cálculos de multiplicação e do cálculo da metragem quadrada. Infere-se assim que uma atividade como a proposta pode contemplar diversos campos da Matemática. Pela descrição das estratégias, conclui-se que houve ideias distintas. Algumas sobressaíram em função de peculiaridades. Assim, entende-se que os objetivos propostos foram atendidos nos cálculos, no raciocínio e na escrita dos projetos. O trabalho foi produtivo e auxiliou os alunos a compreender o papel do administrador de negócios.

Souza et al (2005) ressaltam a importância de desenvolver o raciocínio criativo e a capacidade de resolução de problemas, processo no qual são desenvolvidos o autoconhecimento, o autodesenvolvimento e o pensamento sistêmico, que, de acordo com os autores, possibilitam clareza na percepção do todo e das relações entre as partes e a liderança, o que implica nos requisitos de um administrador, entre as quais citam-se a perseverança, a imaginação e a criatividade, associadas à inovação, passando a ser importante não só o conteúdo que se aprende, mas, sobretudo, como é aprendido. Souza et al (2005) destaca que isso será viável se houver formação que inclua essas características para atingir seus objetivos, adequando conteúdos e práticas didático-pedagógicas a situações reais.

\subsection{RESULTADOS ORIUNDOS DO QUESTIONÁRIO DE AVALIAÇÃO DOS TRABALHOS}

No último dia de aula, ocorreu a apresentação dos trabalhos aos demais colegas da turma. Solicitou-se que avaliassem os trabalhos uns dos outros, a partir de perguntas elaboradas pelas docentes. Ou seja, uma dupla apresentou seu trabalho aos demais, enquanto outros grupos avaliaram a apresentação e o empreendimento apresentado.

A primeira questão: Vocês seriam clientes da empresa/negócio apresentado? Justifiquem.

Todos os alunos responderam que seriam clientes dos negócios dos colegas. Os motivos foram: a estética do local, o nome do empreendimento, a propaganda para atrair mais clientes e o atendimento oferecido, entre outros aspectos positivos, como a organização dos slides na apresentação e a veracidade dos dados apresentados. No entanto, houve críticas, pois

\footnotetext{
faltaram coisas de extrema importância, como, por exemplo: Nós como clientes gostaríamos de visualizar um cardápio para saber as opções e quem sabe o prato do dia e até mesmo as novidades e faltou a demonstração de pagamento, como por exemplo: as comandas para o controle (Aluno 16).
}

Logo, os alunos também foram críticos na avaliação dos colegas.

A outra questão foi: Citem pontos positivos e a melhorar do trabalho apresentado. 
Nessa questão, diversas características foram apontadas tais como: nome criativo, propaganda utilizada, sistema de telebusca, preços competitivos, bom planejamento, o entretenimento do/no local. Seguem algumas falas:

Negócio bem planejado, com pesquisa de mercado para a cidade de Encantado. Expectativa de bom faturamento e detalhes nas demonstrações dos assuntos estudados na disciplina (Aluno 4).

Para Barros (2010), a pesquisa de mercado é utilizada quando o foco estratégico busca informações sobre o que é e por que é importante para o consumidor. Tal tarefa deve ser realizada pelo administrador, pois essa pesquisa é útil para a empresa que quer um produto diferenciado na sociedade. Outros citaram pontos mais específicos de empresa, como:

Bem preocupados com questões como registrar a empresa. Bastante completo os dados apresentados. Abordou os diversos assuntos aprendidos no semestre. Bastante amplo os temas abordados, conseguiram desenvolver bem o andamento do trabalho (Aluno 8).

A partir disso, os alunos citaram pontos que deveriam/poderiam ser melhorados no trabalho apresentado. Cabe salientar a relevância do feedback, que é um aliado dos gestores, já que permite que organização ou indivíduo sejam avaliados de acordo com a sua competência. Na Administração, feedback

é o procedimento que consiste no provimento de informação a uma pessoa sobre o desempenho, conduta, eventualidade ou ação executada por esta, objetivando orientar, reorientar e/ou estimular uma ou mais ações de melhoria, sobre as ações futuras ou executadas anteriormente (CONSONI, 2010, p. 24).

Assim sendo, esse recurso foi importante no desenvolvimento dos trabalhos para dar um "retorno" aos colegas sobre seus negócios, para que visualizassem e refletissem sobre alguns aspectos pertinentes e pequenas inconsistências percebidos pelos alunos avaliadores. Destacase que, nos retornos, ainda foram citados: a necessidade de mais dados, a criatividade e a organização. Também mencionaram que a margem de lucro de alguns era muito baixa, o que dificulta o negócio; ainda, em alguns casos, houve muito investimento para pouco lucro.

Por fim, solicitou-se que os grupos avaliassem o trabalho dando uma nota ao trabalho dos colegas. Neste quesito, os grupos atribuíram a média 7,27, o que mostra que alguns pontos podem ser melhorados numa futura exploração. O que "baixou" a média da nota foram alguns pontos negativos como a falta de dados suficientes para o trabalho, altos investimentos das empresas, a pouca descrição da empresa em si e a falta de criatividade. No final da aula, solicitou-se que todos os alunos respondessem um questionário que contemplou alguns dados pessoais (ramo do trabalho em que atuam, idade, curso), a metodologia aplicada pelas docentes 
no decorrer do semestre (o que acharam, contribuições, reclamações, sugestão de melhorias para a disciplina) e habilidades adquiridas com esse trabalho.

Em relação ao emprego dos participantes, pode-se dividi-los em quatro áreas: outros setores, parte administrativa, parte financeira e os que não trabalham. Assim, constatou-se que 21 alunos atuam em outras áreas (como assistentes, gerentes, coordenadores, indústria, entre outras). Na parte financeira trabalham 6 discentes e na administração, 11 participantes. Quatro alunos ainda não atuam profissionalmente. Pode-se analisar os dados no Gráfico 1 a seguir:

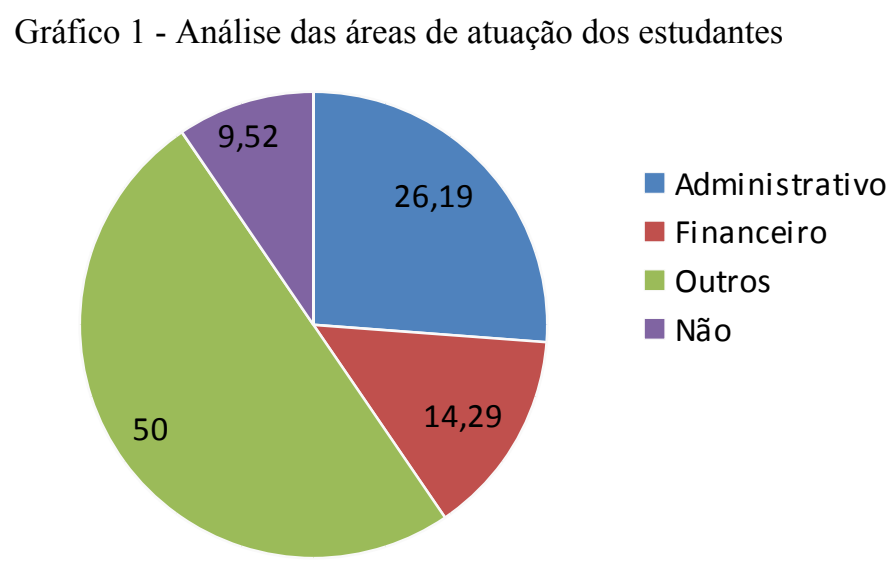

Fonte: Das autoras, 2018.

A respeito da metodologia aplicada pelas professoras, todos os alunos julgaram-na boa, pois os auxiliou a compreender mais e melhor a Matemática. Os alunos sugerem que nas próximas versões da disciplina poderia haver mais polígrafos e outros materiais digitalizados, para fixar melhor o conteúdo antes do trabalho conclusivo. Ainda, citaram que seria interessante trabalhar com menos conteúdos, mas de forma mais aprofundada.

Convém que o professor também seja avaliado, já que as avaliações dos discentes refletem o modo como o professor ensina, isto é, os processos de ensino e de aprendizagem. $\mathrm{Ou}$ seja, a aprendizagem do aluno tem relação com o ensino do educador. Ainda, se as avaliações dos estudantes são positivas, é consequência do ensino e da aprendizagem. Entretanto, se as avaliações não forem positivas, é necessário que o professor busque formas de aperfeiçoar-se, do mesmo modo que um administrador.

Cabe frisar a importância dessa disciplina e a metodologia aplicada, que despertaram um olhar crítico e a aplicação do aprendizado adquirido durante o semestre, sendo o professor também avaliado. Ainda, segundo os alunos, os cálculos são fundamentais; até as pessoas da área de humanas se apaixonariam pela Matemática, aplicando tal método. 


\section{CONSIDERAÇÕEs FinAIS}

Durante o estudo realizado, constatou-se que os alunos se envolveram na atividade proposta para sanar suas dúvidas, pesquisaram além do solicitado e refletiram sobre a relação teoria/prática. Assim, segundo o referencial teórico, a relação da Matemática com o curso de Administração envolve a habilidade de lidar com números e o uso do raciocínio e do pensamento lógico, demonstrativo, intuitivo, criador, reflexivo. Por essas razões, há uma relação de proximidade dos conteúdos de matemática e de administração (FONSECA e SILVA, 2012), o que se percebe nos empreendimentos apresentados pelos grupos de alunos das duas turmas. Em relação aos temas/assuntos abordados nos estudos, a maioria optou pelo ramo alimentício, devido ao seu espaço no cotidiano. Foram elaborados projetos envolvendo restaurantes, pub, lugares de entretenimento e similares.

A elaboração do empreendimento proporcionou a aplicabilidade de diversos conteúdos, como, por exemplo, o uso de escala, importante não somente para profissionais que queiram seguir no ramo da arquitetura e afins, mas, também, para futuros administradores, pois, possivelmente, terão que administrar uma reforma e necessitarão deste conteúdo. Outro fato a ser comentado é o uso de gráficos, que, por mais que pareça "fácil" criá-los, é de extrema importância observar os detalhes, o que foi perceptível nos trabalhos analisados. Salienta-se, ainda, o negócio intitulado "S.O. S Beleza", cujas proprietárias avaliaram o volume de uma estante no local onde a propriedade seria instalada, junto com a cubagem de livros cabíveis na respectiva escrivaninha. Assim, infere-se que os alunos perceberam a aplicabilidade da matemática para um administrador e como poderá lidar com tais situações no dia a dia.

Em termos de avaliação, um dos aspectos relevantes foi o pensamento, a criatividade e as estratégias utilizadas pelos discentes. Destaca-se que a forma de avaliação foi essencial para dar um "retorno" aos colegas sobre seus negócios, de modo que cada grupo refletisse sobre aspectos pertinentes e pequenos erros que os alunos avaliadores perceberam. Salienta-se que a metodologia proposta no decorrer da disciplina necessitou de planejamento, organização e conhecimento por parte dos docentes envolvidos. Ademais, cabe aos educadores proporem atividades diferenciadas com métodos avaliativos diferentes, proporcionando aos alunos a reflexão sobre aquilo que estão fazendo.

Resumindo, acredita-se que a metodologia utilizada pelas professoras do curso foi importante, pois: a) despertou um olhar crítico; b) houve aplicação dos conteúdos explorados durante o semestre no trabalho final; c) tanto o docente quanto os discentes foram avaliados; d) 
os alunos concluíram que os cálculos são fundamentais para sua área e comentam que até mesmo o pessoal de humanas se apaixonaria pela Matemática se fosse aplicado tal método.

\section{REFERÊNCIAS}

BARROS, Pupe André. A importância da pesquisa de mercado e inovação para empresas de sonorização e iluminação de eventos do Distrito Federal: um estudo de caso da Marc Systems. 2010. 23 f. Trabalho de conclusão curso - Centro Universitário de Brasília, Brasília. Disponível em: $<$ https://repositorio.uniceub.br/jspui/bitstream/235/9199/1/20800101.pdf $>$. Acesso em: 09 abr. 2019.

CASTRO, Iná Elias. O problema da escala. In: CASTRO, Iná Elias de; CORREA, Roberto Lobato; GOMES, Paulo Cesar da Costa. (Organizadores) Geografia: conceitos e temas. Rio de Janeiro: Bertrand Brasil, 1995. p. 117-140.

CONSONI, Bianca. A importância do feedback. 2010. 54 f. Trabalho de conclusão curso Fundação Educacional do Município de Assis, Assis.

EDUCACIONAL, Grupo Cruzeiro do Sul. Guia: O perfil do profissional de Administração. Blog Unipê. 2016. Disponível em:

$<$ http://blogcarreiras2.cruzeirodosuleducacional.edu.br/graduacao/guia-o-perfil-doprofissional-de-administracao/>. Acesso em: 03 jan, 2020.

ESQUIVEL, Gilceli da Silva; SANTANA, Nilo Félix Gagliano de; ALVES, Thiago Tude de Sá; FARIAS, Vitor Tavares. A importância da matemática para o administrador de empresas. 2008. Disponível em:

$<$ http://www.ebah.com.br/content/ABAAAAH54AC/aimportancia-matematicanaadministracao>. Acesso em: 05 fev. 2019.

FERREIRA, Sidnei Barbosa; SILVA, Janete Pereira da. A importância da Matemática para o Administrador de Empresas. In: $2^{\circ}$ Encontro de Iniciação Científica da Faculdade Apogeu, 2012, Apogeu. Trabalhos. Disponível em:

$<$ https://www.yumpu.com/pt/document/read/12539832/a-importancia-da-matematica-para-oadministrador-de-empresas $>$. Acesso em: 06 fev. 2019.

FONSECA, Ricardo de Freitas; SILVA, Wendel Alex Castro. A relação entre o curso de administração, os acadêmicos e a disciplina de Matemática: Uma reflexão. In: IX Convibra Administração - Congresso Virtual Brasileiro de Administração. 2012. Disponível em: $<$ http://www.convibra.com.br/upload/paper/2012/31/2012_31_4363.pdf $>$. Acesso em: 06 fev. 2019.

FREITAS, Wesley Ricardo de Souza; JABBOUR, Charbel José Chiapetta. Utilizando estudo de caso(s) como estratégia de pesquisa qualitativa: boas práticas e sugestões. Lajeado: Estudo \& Debate, v. 18, n. 2, p. 07-22, 2011.

FUENTES, Verônica Lídia Peñaloza; LIMA, Ronaldo; GUERRA, Diego de Sousa. Atitudes em relação à matemática em estudantes de Administração. Revista Semestral da Associação Brasileira de Psicologia Escolar e Educacional (ABRAPEE), v. 13, n. 1, p. 133-141. 2009. 
FUTURO, Débora Omena; SILVA, Ronaldo Ferreira da. Uso de ferramentas de controle estatístico para o entendimento do processo de produção de cápsulas em farmácias magistrais. In: Encontro Nacional de Engenharia de Produção. Foz do Iguaçu. Anais. Paraná, 2007.

GODOY, Arilda Schmidt. Pesquisa qualitativa: Tipos fundamentais. São Paulo: Revista de administração de empresas, v.35, n.3, p. 20-29, 1995.

INDEED. Vagas de emprego: Administrador requisitos. Disponível em:

$<$ https://www.indeed.com.br/empregos-de-Administrador-Requisitos $>$. Acesso em: 09 abr.2019.

KOHN, Karen; MORAES, Cláudia Herte de. O impacto das novas tecnologias na sociedade: conceitos e características da Sociedade da Informação e da Sociedade Digital. In: XXX Congresso Brasileiro de Ciências da Comunicação. 2007. Disponível em:

$<$ https://www.intercom.org.br/papers/nacionais/2007/resumos/R1533-1.pdf $>$. Acesso em: 08 abr. 2019.

LISBOA, Josiane Mostasso; LUCINO, Micheli Aparecida. A importância da teoria e da prática nas aulas de Matemática. 2015. $48 \mathrm{f}$. Trabalho de conclusão curso - Faculdades Integradas do Vale do Ivaí, Ivaiporã.

MACHADO, Antônio. Matemática na escola do segundo grau. A matemática e as profissões. v. 2. São Paulo: Atual, 1998.

MONTEIRO, Carlos Eduardo Ferreira. Interpretação de gráficos sobre economia veiculados pela mídia impressa. Dissertação de Mestrado. Pós-Graduação em Psicologia da UFPE, Recife-PE, 1998.

MOREIRA, Marco Antônio. Metodologias de pesquisa em ensino. 1 ed. São Paulo: Editora Livraria de Física, 2011.

SANTOS, Andréia Kohatsu; CAPELARI, Rosana; SPERANDIO, Décio. É relevante o estudo da Matemática na formação do administrador contemporâneo? s/data. Disponível em:

$<$ http://www.angrad.org.br/_resources/files/_modules/producao/producao_481_20121205183 4228e9c.pdf>. Acesso em: 05 fev. 2019.

SANTOS, Josiel Almeida; FRANÇA, Kleber Vieira; SANTOS, Lúcia S. B. dos.

Dificuldades de aprendizagem de Matemática. 2007. $41 \mathrm{f}$. Trabalho de conclusão curso Universitário Adventista de São Paulo, São Paulo.

SEBRAE - Embraer. Setor de Alimentos: estabelecimentos e empregos formais no Rio de Janeiro. $\mathrm{N}^{\circ}$ 18, 2012. Disponível em:

$<$ http://www.sebrae.com.br/sites/PortalSebrae/ufs/rj/institucional/observatorionotasconjunturais,b99d6e69cfb56410VgnVCM2000003c74010aRCRD>. Acesso em: 07 fev. 2019.

SERRANO, Glória Pérez. Investigación cualitativa. Retos e interrogantes. I. Métodos. Madrid: La Muralla S.A. 1998. 
SILVA, Dione Morais da. O administrador do século XXI. 2015. 43 f. Trabalho de conclusão curso - Instituto Municipal de Ensino Superior de Assis, Assis.

SILVEIRA, Marisa Rosâni Abreu da. "Matemática é difícil”: um sentido pré-construído evidenciado na fala dos alunos. Disponível em:

$<$ http://www.ufrrj.br/emanped/paginas/conteudo_producoes/docs_25/matematica.pdf $>$.

Acesso em: 15, mai, 2019.

SOUZA, Helcimara Affonso de. Teoria geral da Administração. 1 ed. Rio de Janeiro: Seses, 2015. 354 p.

SOUZA, Eda Castro Lucas de; SOUZA, Cristina Castro Lucas de; ASSIS, Simone de Araújo Góes; ZERBINI, Thais. Métodos, técnicas e recursos didáticos de ensino de empreendedorismo em IES brasileiras. Empreendedorismo além do plano de negócio. São Paulo: Editora Atlas, 2005

Recebido em: 14 de abril de 2019.

Aprovado em: 17 de junho de 2019. 